\title{
Reclassification of Nocardioides simplex ATCC 13260, ATCC 19565, and ATCC 19566 as Rhodococcus erythropolis
}

\author{
JUNG-HOON YOON,,${ }^{1,2}$ JUNG-SOOK LEE, ${ }^{1}$ YONG KOOK SHIN, ${ }^{1}$ YONG-HA PARK, ${ }^{1}$ \\ AND SUNG TAIK LEE ${ }^{2 *}$ \\ Bioinformatics \& Systematics Laboratory, Korean Collection for Type Cultures, Korea Research Institute of Bioscience \\ and Biotechnology, Korea Institute of Science and Technology, Daeduk Science Park, ${ }^{1}$ and Department of Biological \\ Sciences, Korea Advanced Institute of Science and Technology, ${ }^{2}$ Taejeon, Republic of Korea
}

\begin{abstract}
Our phylogenetic analysis based on 16S ribosomal DNA (rDNA) sequences and chemotaxonomic analyses showed that Nocardioides simplex ATCC 13260, ATCC 19565, and ATCC 19566 are more closely related to the genus Rhodococcus, especially Rhodococcus erythropolis, than to the genus Nocardioides. $N$. simplex ATCC 13260 and $N$. simplex ATCC 19565 and ATCC 19566 exhibited levels of 16 rDNA similarity of 99.4 and $100 \%$, respectively, to $R$. erythropolis DSM 43066 ${ }^{T}$. Strains ATCC 13260, ATCC 19565, and ATCC 19566 had mesodiaminopimelic acid in their peptidoglycan and $\mathrm{MK}-8\left(\mathrm{H}_{2}\right)$ as their predominant menaquinone. These three strains produced cellular fatty acid patterns similar to those of $R$. erythropolis strains rather than those of Nocardioides species. Therefore, $N$. simplex ATCC 13260, ATCC 19565, and ATCC 19566 should be reclassified as strains of $R$. erythropolis Gray and Thornton 1928.
\end{abstract}

Arthrobacter simplex was assigned to the genus Nocardioides as Nocardioides simplex by O'Donnell et al. in 1982 (9). Suzuki and Komagata proposed that the genus Pimelobacter should accommodate Arthrobacter species containing LL-diaminopimelic acid in their peptidoglycan (14). Arthrobacter globiformis, the type species of the genus Arthrobacter, contains lysine as the dibasic amino acid in its peptidoglycan (12). A strain of Arthrobacter simplex and two strains of "Brevibacterium lipolyticum" were assigned to Pimelobacter simplex, and the name Pimelobacter jensenii was proposed for an atypical Arthrobacter simplex strain (14). However, $P$. simplex and $P$. jensenii were found to be indistinguishable from members of the genus $\mathrm{No}$ cardioides with respect to certain chemotaxonomic traits $(3,9)$. These two taxa were shown to be related to the genus Nocardioides by phylogenetic inferences based on 16S rRNA sequences (1). Therefore, $P$. simplex and $P$. jensenii have been described as members of the genus Nocardioides (1).

$N$. simplex is distinguishable from other Nocardioides species by its motility and does not form an extended substrate and aerial mycelium (14). Some strains of $N$. simplex, including industrially significant patented strains, have been described. However, some strains of $N$. simplex, N. simplex ATCC 13260 , ATCC 19565, and ATCC 19566, differ from the type strain of $N$. simplex in colonial morphology. Therefore, we compared these strains with the type strain of $N$. simplex by using chemotaxonomic markers and $16 \mathrm{~S}$ ribosomal DNA (rDNA) sequences.

N. simplex ATCC 13260, ATCC 19565, and ATCC 19566 were purchased from American Type Culture Collection in 1996 and were grown in shake flasks containing tryptone soy broth supplemented with glucose $(0.75 \%$, wt $/ \mathrm{vol})$ at $26^{\circ} \mathrm{C}$. The broth cultures were checked for purity before they were harvested by centrifugation. Chromosomal DNA was isolated and purified by a method described previously (16). The $16 \mathrm{~S}$ rDNA sequences were determined by directly se-

\footnotetext{
* Corresponding author. Mailing address: Department of Biological Sciences, Korea Advanced Institute of Science and Technology, 373-1 Kusong-dong, Yusong-gu, Taejeon 305-701, Republic of Korea. Phone: 82-42-869-2617. Fax: 82-42-869-5617. E-mail: stlee@sorak .kaist.re.kr.
}

quencing nonphosphorylated strands of PCR-amplified $16 \mathrm{~S}$ rDNAs whose 5'-phosphorylated strands were selectively digested by $\lambda$ exonuclease. Two previously described primers (13), primers 9F (5'-GAGTTTGATCCTGGCTCAG-3'; positions 9 to 27 [Escherichia coli 16S rRNA numbering]) and 1542R (5'-AGAAAGGAGGTGATCCAGCC-3'; positions 1542 to 1525 [E. coli $16 \mathrm{~S}$ rRNA numbering]), were used for amplification of the 16S rRNA gene. The $5^{\prime}$ ends of the two primers were phosphorylated by using T4 polynucleotide kinase (New England Biolabs, Inc., Beverly, Mass.) according to the instructions included in a Strandase ssDNA preparation kit (Novagen, Inc., Madison, Wis.). The 16S rRNA gene was amplified as described previously (17) by using phosphorylated primer 9F plus nonphosphorylated primer 1542R and phosphorylated primer $1542 \mathrm{R}$ plus nonphosphorylated primer $9 \mathrm{~F}$. The PCR products were precipitated with $1 \mu \mathrm{l}$ of $1 \%$ (wt/vol) glycogen, $9 \mu \mathrm{l}$ of $3 \mathrm{M}$ sodium acetate $(\mathrm{pH} 5.2)$, and $70 \mu \mathrm{l}$ of isopropanol and were resuspended in $10 \mu \mathrm{l}$ of distilled water.

The strand containing the phosphorylated primer from the PCR product was selectively digested with $\lambda$ exonuclease according to the instructions of the Strandase ssDNA preparation kit. The single-stranded DNA templates produced were directly used for sequencing. Sequencing was performed as described previously (7) by using $\alpha-{ }^{35}$ S-labelled dATP and a DNA sequencing kit (U.S. Biochemicals, Cleveland, Ohio) and by using primers derived from conserved regions of the $16 \mathrm{~S}$ rRNA gene. The $16 \mathrm{~S}$ rDNA sequences of $N$. simplex ATCC 13260, ATCC 19565, and ATCC 19566 were aligned with the 16S rRNA sequences of representatives of the genera Nocardioides and Rhodococcus and some other actinomycete taxa by using CLUSTAL W software (15). Gaps at the $5^{\prime}$ and $3^{\prime}$ ends of the alignment were omitted from further analysis. Evolutionary distances calculated by using the Kimura-2 parameter correction with CLUSTAL W software were used to construct a phylogenetic tree by the neighbor-joining method (11).

The diamino acid of the peptidoglycan was determined by a method described previously (8). Menaquinones were analyzed as described previously (6) by using reverse-phase highperformance liquid chromatography. Nocardioides albus KCTC $9186^{\mathrm{T}}$, Nocardioides jensenii KCTC $9134^{\mathrm{T}}$, Nocardioides luteus KCTC $9575^{\mathrm{T}}$, N. simplex KCTC $9106^{\mathrm{T}}$, ATCC 13260 , ATCC 19565, and ATCC 19566, and Rhodococcus erythropolis 


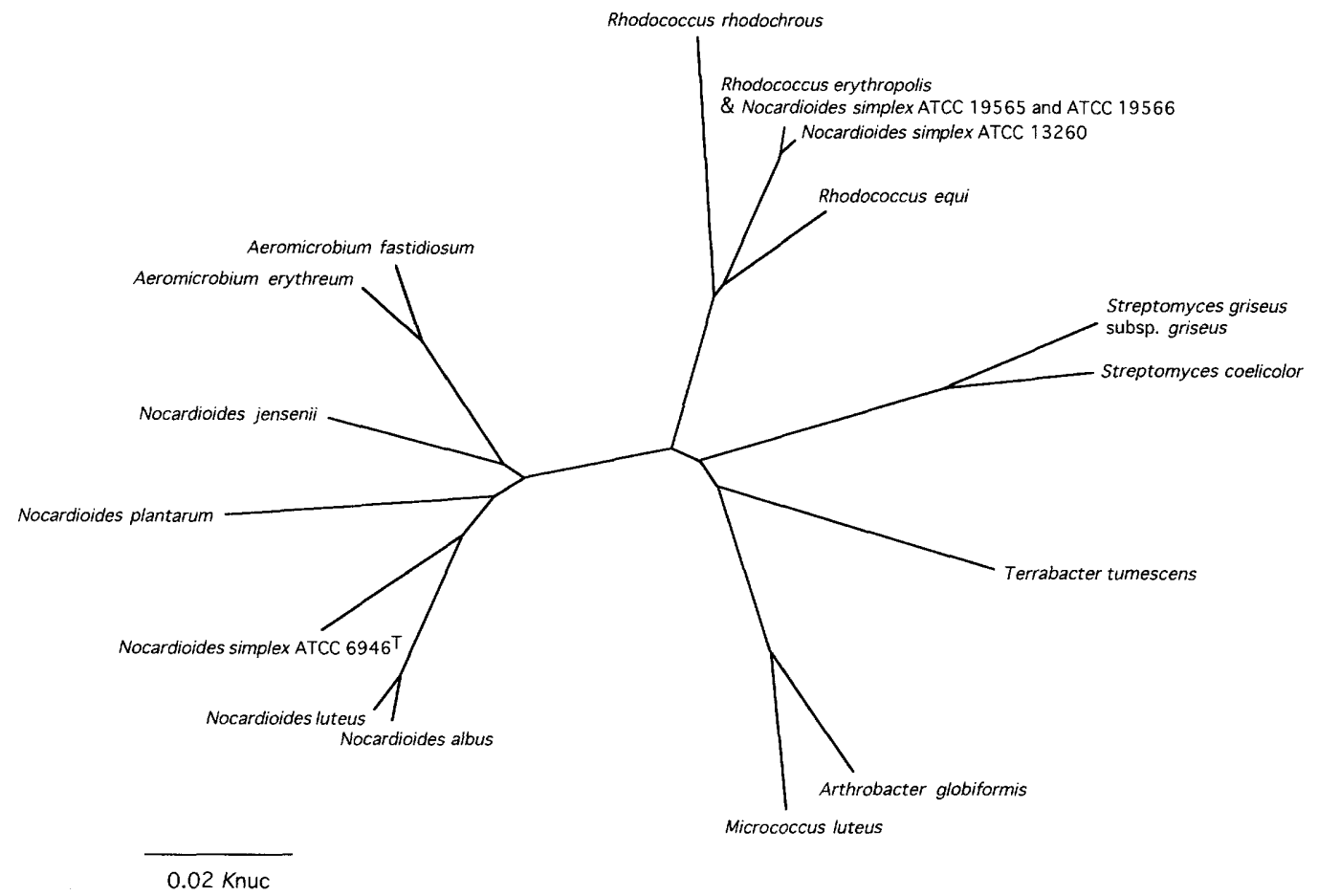

FIG. 1. Unrooted phylogenetic tree showing the positions of N. simplex ATCC 13260, ATCC 19565, and ATCC 19566, of representatives of the genera Nocardioides and Rhodococcus, and of some other actinomycete taxa.

KCTC 1062 ${ }^{\mathrm{T}}$, KCTC 1061, and KCTC 9077 were also grown for 4 days on nutrient agar (Difco) for a fatty acid methyl ester analysis. Fatty acids were extracted and analyzed by using the instructions of the Microbial Identification System (Microbial ID, Inc., Newark, Del.).

N. simplex ATCC 13260, ATCC 19565, and ATCC 19566 exhibited low levels of $16 \mathrm{~S}$ rDNA similarity with Nocardioides strains, including the type strain of $N$. simplex, and a closer relationship with Rhodococcus species. N. simplex ATCC 19565 and ATCC 19566 had the same 16S rDNA sequence and exhibited levels of $16 \mathrm{~S}$ rDNA similarity of $90.1 \%$ with the type strain of $N$. simplex and 89.1 to $90.3 \%$ with other Nocardioides species. N. simplex ATCC 19565 and ATCC 19566 had 16S rDNA sequences that were identical to the $R$. erythropolis DSM $43066^{T} 16 \mathrm{~S}$ rDNA sequence in the region corresponding to the region between positions 28 and 1524 in the $16 \mathrm{~S}$ rRNA of $E$. coli. N. simplex ATCC 13260 exhibited a level of 16S rDNA similarity of $99.3 \%$ with $N$. simplex ATCC 19565 and ATCC 19566. N. simplex ATCC 13260 also exhibited levels of $16 \mathrm{~S}$ rDNA similarity of $90 \%$ with the type strain of N. simplex, 89 to $90.4 \%$ with other Nocardioides species, and $99.4 \%$ with $R$. erythropolis DSM $43066^{\mathrm{T}}$. Therefore, $N$. simplex ATCC 13260 , ATCC 19565, and ATCC 19566 are thought to be strains of $R$. erythropolis Gray and Thornton 1928 (5) rather than strains of N. simplex (Fig. 1).

Chemotaxonomic traits of $N$. simplex ATCC 13260, ATCC 19565, and ATCC 19566 also provide supporting evidence that these three strains are members of the genus Rhodococcus rather than the genus Nocardioides. N. simplex ATCC 13260, ATCC 19565, and ATCC 19566 have meso-diaminopimelic acid as the dibasic amino acid in their cell wall peptidoglycan. Rhodococcus strains have been known to have meso-diaminopimelic acid in their cell walls (12). However, the genus $\mathrm{No}$ cardioides is one of the few taxa that contain LL-diaminopimelic acid in the cell wall $(1,10)$. N. simplex ATCC 13260, ATCC 19565, and ATCC 19566 have a dihydrogenated menaquinone with eight isoprene units [MK- $\left.8\left(\mathrm{H}_{2}\right)\right]$ as their predominant quinone. The predominant menaquinones found in the genus Rhodococcus and the genus Nocardioides are MK- $8\left(\mathrm{H}_{2}\right)(2,4)$ and $\mathrm{MK}-8\left(\mathrm{H}_{4}\right)(9)$, respectively. In the cellular fatty acid methyl ester analysis, $N$. simplex ATCC 13260, ATCC 19565 , and ATCC 19566 produced patterns similar to those of $R$. erythropolis strains but different from those of Nocardioides species (Table 1). N. simplex ATCC 13260, ATCC 19565, and ATCC 19566 and strains of $R$. erythropolis were found to contain a significant amount of $\mathrm{C}_{16: 0}$ and 10-methyl-branched $\mathrm{C}_{18: 0}$ as major fatty acids, whereas Nocardioides species, including the type strain of $N$. simplex contained iso- $\mathrm{C}_{16: 0}$ as the major fatty acid.

Our phylogenetic analysis based on $16 \mathrm{~S}$ rDNA sequences and chemotaxonomic analyses showed that $N$. simplex ATCC 13260, ATCC 19565, and ATCC 19566 are more closely related to the genus Rhodococcus, especially $R$. erythropolis, than to the type strain of $N$. simplex. Therefore, we propose that $N$. simplex ATCC 13260, ATCC 19565, and ATCC 19566 should be reclassified as strains of $R$. erythropolis Gray and Thornton 1928.

Nucleotide sequence accession numbers. The $16 \mathrm{~S}$ rRNA gene sequences of $N$. simplex ATCC 13260, ATCC 19565, and ATCC 19566 have been deposited in the GenBank database under accession no. U81990, U82666, and U82667, respectively. The accession numbers for the sequences used as reference sequences are as follows: $N$. albus, X53211; N. jensenii, X53214; N. luteus, X53212; Nocardioides plantarum, X69973; Aeromicrobium erythreum, M37200; Aeromicrobium fastidiosum, X53189; Terrabacter tumescens, X53215; Rhodococcus rhodochrous, X70295; R. erythropolis, M79289; Rhodococcus equi, X80614; Streptomyces griseus subsp. griseus, M76388; 
TABLE 1. Cellular fatty acid profiles of representatives of the genus Nocardioides, N. simplex ATCC 13260, ATCC 19565, and ATCC 19566, and some strains of R. erythropolis

\begin{tabular}{|c|c|c|c|c|c|c|c|c|c|c|}
\hline \multirow[b]{2}{*}{$\begin{array}{l}\text { Fatty acid or summed } \\
\text { feature }\end{array}$} & \multicolumn{10}{|c|}{$\%$ in: } \\
\hline & 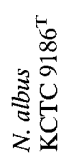 & 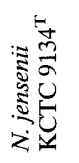 & 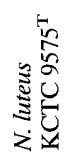 & 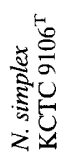 & 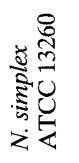 & 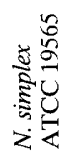 & 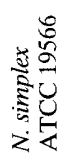 & 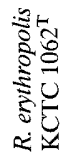 & 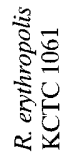 & 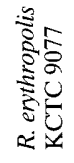 \\
\hline \multicolumn{11}{|l|}{ Saturated fatty acids } \\
\hline $14: 0$ & & & & & 5.4 & 5.6 & 5.5 & 5.5 & 4.8 & 4.7 \\
\hline $15: 0$ & 0.7 & 0.3 & & & 3.1 & 3.2 & 2.6 & 1.6 & 1.9 & 2.8 \\
\hline $16: 0$ & 0.7 & 1.3 & 0.6 & 1.1 & 24.0 & 25.9 & 25.7 & 20.2 & 23.2 & 24.7 \\
\hline $17: 0$ & 1.5 & 2.7 & 0.5 & & 1.4 & & & 1.4 & 1.3 & 1.4 \\
\hline $18: 0$ & & 2.0 & & 1.3 & 0.7 & 1.5 & & 0.8 & 0.9 & 0.7 \\
\hline 19:0 & & & & & 3.8 & 5.7 & 5.6 & 7.1 & 6.6 & 5.5 \\
\hline $20: 0$ & & & & & 2.0 & 2.9 & 2.6 & 1.9 & 2.8 & 2.4 \\
\hline \multicolumn{11}{|l|}{ Unsaturated fatty acids } \\
\hline $15: 1 \omega 5 \mathrm{c}$ & & & & & 0.4 & & & 0.5 & 0.4 & \\
\hline $15: 1 \omega 6 c$ & & 0.3 & & & & & & & & \\
\hline $16: 1 \omega 9 \mathrm{c}$ & & & & & 0.4 & & & & & \\
\hline $17: 1 \omega 5 \mathrm{c}$ & & & & & 3.9 & 4.9 & 5.1 & 6.3 & 5.3 & 4.6 \\
\hline $17: 1 \omega 6 c$ & 15.6 & 5.2 & 15.9 & 13.1 & & & & & & \\
\hline $17: 1 \omega 8 c$ & 2.8 & 3.4 & 1.1 & 2.3 & 1.3 & 2.1 & & 1.2 & 1.3 & 1.4 \\
\hline $18: 1 \omega 9 c$ & & 3.3 & & 7.3 & 3.2 & 3.0 & 2.9 & 4.4 & 7.5 & 6.8 \\
\hline $19: 1$ iso I & & & & 1.6 & & & & & & \\
\hline $20: 2 \omega 6,9 c$ & & & & & & & & 0.8 & 0.9 & 1.0 \\
\hline \multicolumn{11}{|l|}{ Branched fatty acids } \\
\hline iso- $14: 0$ & 2.2 & 1.1 & 0.7 & 1.6 & & & & & & \\
\hline iso-14:0 3-OH & & & 0.6 & & & & & & & \\
\hline iso- $15: 0$ & 3.1 & 3.7 & 3.7 & 1.5 & & & & & & \\
\hline iso- $16: 1 \mathrm{H}$ & 1.1 & 14.0 & 2.1 & 5.4 & & & & & & \\
\hline iso-16:0 & 53.6 & 45.5 & 49.1 & 34.4 & & & & & & \\
\hline iso-17:0 & 1.3 & 1.7 & 1.0 & 2.2 & & & & & & \\
\hline anteiso-17:0 & 0.7 & 0.7 & 1.4 & 0.5 & & & & & & \\
\hline iso-18:0 & 0.9 & 2.7 & & 0.9 & & & & & & \\
\hline \multicolumn{11}{|l|}{$\begin{array}{l}\text { 10-Methyl-branched } \\
\text { fatty acids }\end{array}$} \\
\hline $16: 0$ & 1.5 & 2.5 & 5.0 & 4.0 & 1.8 & 1.6 & 1.8 & 3.2 & 1.6 & 1.2 \\
\hline $17: 0$ & 12.2 & 5.4 & 15.0 & 5.4 & 2.9 & 3.1 & 2.7 & 1.7 & 1.4 & 2.1 \\
\hline $18: 0$ & 2.3 & 2.4 & 2.9 & 9.3 & 29.0 & 29.7 & 33.0 & 25.4 & 22.5 & 26.1 \\
\hline $19: 0$ & & & & & 1.0 & & 1.2 & 0.9 & 0.7 & 0.8 \\
\hline \multicolumn{11}{|l|}{ Summed features ${ }^{a}$} \\
\hline Summed feature 4 & & 1.2 & & 5.1 & 14.4 & 9.4 & 11.3 & 14.7 & 14.9 & 12.2 \\
\hline Summed feature 6 & & & & 0.7 & & & & & & \\
\hline Summed feature 7 & & & & 2.4 & & & & & & \\
\hline Summed feature 8 & & & & & 1.4 & 1.5 & & 1.5 & 1.6 & 1.6 \\
\hline
\end{tabular}

" Summed features represent groups of two or three fatty acids which could not be separated by gas-liquid chromatography with the MIDI system. Summed feature 4 contained one or more of the following fatty acids: iso-15:0 2-OH and/or 16:1 $1 \mathrm{c}$. Summed feature 6 contained one or more of the following fatty acids: anteiso-18:0 and/or $18: 2 \omega 6,9 \mathrm{c}$. Summed feature 7 contained one or more of the following fatty acids: 18:1 $\omega 7 \mathrm{c}, 18: 1 \omega 9 \mathrm{t}$, and/or 18:1 $\omega 12 \mathrm{t}$. Summed feature 8 contained one or more of the following fatty acids: unknown 18.756 and/or 19:1 $\omega 11 \mathrm{c}$.

Streptomyces coelicolor, X60514; Arthrobacter globiformis, M23411; and Micrococcus luteus, M38242. The 16 S rRNA sequence of the type strain of $N$. simplex was obtained from the study of Collins et al. (1).

This work was supported by grant HS1331 from the Ministry of Science and Technology of the Republic of Korea.

\section{REFERENCES}

1. Collins, M. D., M. Dorsch, and E. Stackebrandt. 1989. Transfer of Pimelobacter tumescens to Terrabacter gen. nov. as Terrabacter tumescens comb. nov. and of Pimelobacter jensenii to Nocardioides as Nocardioides jensenii comb. nov. Int. J. Syst. Bacteriol. 39:1-6.

2. Collins, M. D., M. Goodfellow, D. E. Minnikin, and G. Alderson. 1985. Menaquinone composition of mycolic acid-containing actinomycetes and some sporoactinomycetes. J. Appl. Bacteriol. 58:77-86.

3. Collins, M. D., R. M. Keddie, and E. Kroppenstedt. 1983. Lipid composition of Arthrobacter simplex, Arthrobacter tumescens and possibly related taxa. Syst. Appl. Microbiol. 4:18-26.
4. Collins, M. D., T. Pirouz, M. Goodfellow, and D. E. Minnikin. 1977. Distribution of menaquinones in actinomycetes and corynebacteria. J. Gen. Microbiol. 100:221-230.

5. Gray, P. H. H., and H. G. Thornton. 1928. Soil bacteria that decompose certain aromatic compounds. Zentralbl. Bakteriol. Parasitenkd. Infektionskr. Hyg. Abt. II 73:74-96.

6. Hiraishi, A., Y. K. Shin, J. Sugiyama, and K. Komagata. 1992. Isoprenoid quinones and fatty acids of Zoogloea. Antonie Leeuwenhoek 61:231-236

7. Kim, S.-B., J.-H. Yoon, H. Kim, S. T. Lee, Y.-H. Park, and M. Goodfellow. 1995. A phylogenetic analysis of the genus Saccharomonospora conducted with 16S rRNA gene sequences. Int. J. Syst. Bacteriol. 45:351-356.

8. Komagata, K., and K. I. Suzuki. 1987. Lipids and cell-wall analysis in bacterial systematics. Methods Microbiol. 19:182-190.

9. O'Donnell, A. G., M. Goodfellow, and D. E. Minnikin. 1982. Lipids in the classification of Nocardioides: reclassification of Arthrobacter simplex (Jensen) Lochhead in the genus Nocardioides (Prauser) emend O'Donnell et al. as Nocardioides simplex comb. nov. Arch. Microbiol. 133:323-329.

10. Prauser, H. 1976. Nocardioides, a new genus of the order Actinomycetales. Int. J. Syst. Bacteriol. 26:58-65. 
11. Saitou, N., and M. Nei. 1987. The neighbor-joining method: a new method for reconstructing phylogenetic trees. Mol. Biol. Evol. 4:406-425.

12. Schleifer, K. H., and O. Kandler. 1972. Peptidoglycan types of bacterial cell walls and their taxonomic implications. Bacteriol. Rev. 36:407-477.

13. Stackebrandt, E., and W. Liesack. 1993. Nucleic acids and classification, p. 152-189. In M. Goodfellow and A. G. O'Donnell (ed.), Handbook of new bacterial systematics. Academic Press, London, United Kingdom.

14. Suzuki, K.-I., and K. Komagata. 1983. Pimelobacter gen. nov., a new genus of coryneform bacteria with LL-diaminopimelic acid in the cell wall. J. Gen. Appl. Microbiol. 29:59-71.

15. Thompson, J. D., D. G. Higgins, and T. J. Gibson. 1994. CLUSTAL W: improving the sensitivity of progressive multiple sequence alignment through sequence weighting, position specific gap penalties and weight matrix choice. Nucleic Acids Res. 22:4673-4680.

16. Yoon, J.-H., H. Kim, S.-B. Kim, H.-J. Kim, W. Y. Kim, S. T. Lee, M. Goodfellow, and Y.-H. Park. 1996. Identification of Saccharomonospora strains by the use of genomic DNA fragments and rRNA gene probes. Int. J. Syst. Bacteriol. 46:502-505.

17. Yoon, J.-H., S. T. Lee, S.-B. Kim, W. Y. Kim, M. Goodfellow, and Y.-H. Park 1997. Restriction fragment length polymorphism analysis of PCR-amplified 16 S ribosomal DNA for rapid identification of Saccharomonospora strains. Int. J. Syst. Bacteriol. 47:111-114. 